\title{
NEOCIDAL AND CYPERMETHRIN PESTICIDES EXPOSED EWES: THE OVARIAN RECYCLICITY AND THE HORMONAL PROFILES OF THE REPRODUCTIVE SYSTEM DISRUPTED
}

\author{
A.A. KHALAF ${ }^{*}$ and B.R. ABDEL-HALIM ${ }^{* *}$ \\ ${ }_{* *}^{*}$ Department of Forensic Medicine and Toxicology, Faculty of Veterinary Medicine, Cairo University, Giza, Egypt, \\ ** Department of Theriogenology, Faculty of Veterinary Medicine, Beni-Suef University, Beni-Suef, Egypt, Tel. /Fax: \\ 0020822327982 Email: drbakarwa@yahoo.com
}

\section{ABSTRACT}

Received: 25/6/2012

Accepted at: 23/7/2012
This study was designed firstly to investigate whether cypermethrin and Neocidol have effects on length of estrous cycle, estrous recyclicty and reproductive hormones in native ewes. Twenty apparently healthy mature ewes of native breed were used in the current study, sprayed by either neocidol or ectomin by the proper dose (1/1000 and 1/500 respectively) during the breeding season. Synchronization of estrus was performed by using veramix sheep sponges which contain medroxy progesterone acetate. The obtained results revealed that, spraying of ewes by either neocidol or ectomin by the proper dose (1/1000 and 1/500 respectively) during the breeding season had no impairment effect on the length of estrous cycle or estrous recyclicty. It was also noticed that the treatment of ewes with neocidol during the breeding season had no significant $(p<0.05)$ effect on the length of estrous cycle. Moreover, neither neocidol nor ectomin had no significant influence on the classical pattern of progesterone (P4) profiles. The obtained results showed that a similar pattern of FSH in the control, neocidol and ectomin treated ewes. This pattern was in the form of two elevated peaks on zero and first day of estrous cycle and fluctuated till the end of estrous cycle. In addition, LH pattern during estrous cycle was similar in the control and neocidol and ectomin treated ewes, one peak only was recorded at zero day in the three estrous cycles then the level was fluctuated all over the experimental period in all treated and control ewes. From the current study we concluded that neither cypermethrin nor Neocidol had adverse effects on length of estrous cycle, estrous recyclicty and reproductive hormones in native ewes when sprayed by the proper dose (1/1000 and 1/500 respectively).

Keywords: Sheep, ovarian recyclicity, reproductive hormones, cypermethrin, Neocidol.

\section{INTRODUCTION}

Most environmental chemical exposures occur to chemical mixtures at relatively low concentrations. Each of these contaminants individually may increase the risk of certain diseases, but how contaminants interact remains a relatively unexplored subject. The importance of this subject has recently been recognized. Pyrethroids and organophosphates are among the most common pesticides in current use worldwide.

Certain pyrethroids exert hormonal activity that may alter early neurologic and reproductive development. Pyrethroids can elicit a range of immunotoxic and neurotoxic effects in humans and other mammals, and pyrethroid exposure may contribute to reproductive dysfunction, developmental impairment and cancer (Garey and Wolff 1998; Landrigan et al., 1999).
Cypermethrin is a type II pyrethoid pesticide, widely used in agriculture and environmental applications. Institoris et al. (1999) observed several interactions between cypermethrin and the heavy metals $\mathrm{Cd}$ and $\mathrm{Pb}$ with respect to toxicological, hematological, and immune effects. Cypermethrin is also considered an endocrine disruptor. Treatment with cypermethrin caused significant decreases in ejaculate volume, sperm concentration, total sperm output, sperm motility and plasma testosterone (Yousef et al., 2003). It was found that endocrine disruptors are not merely 'reproductive hormones', but affect the functioning of several non reproductive tissues, notably the immune system (Ahmed 2000). Sortur and Kaliwal (1999) found that diazinone (Neocidol) treated rats showed irregular estrous cycles and changes in estrous cycle duration, but no significant change in other reproductive indices. There is little literature about the effects of pyrethoid and 
organophosphate mixtures on the endocrine, reproductive and immune systems.

Estrus synchronization (ES) in livestock focuses on the manipulation of either the luteal or the follicular phase of the estrous cycle. In does and ewes, the opportunity for control is greater during the luteal phase, which is of longer duration and more responsive to manipulation. Strategies can be employed to extend the luteal phase by supplying exogenous progesterone or to shorten this phase by prematurely regressing existing corpora lutea (CL). Successful techniques must not only establish tight synchrony, but also provide an acceptable level of fertility upon artificial insemination or natural mating (Wildeus, 2000). The latter is commonly accomplished through co-treatments using gonadotropin. After these conditions are met, ES becomes the basis for successful AI and embryo transfer programs. A considerable amount of information was produced and published on ES in goats and sheep in the 1970s and 1980s and the foundation was established for much of the research conducted today. In sheep, the length of the estrus cycle ranges from 13 to 19 days and averages 17 days. The phases of the estrous cycle are proestrus, estrus, metestrus, and diestrus. Estrus is the period of time when the ewe is receptive to the ram and will stand for mating. It lasts approximately 24 to 36 hours.

Ovulation occurs in mid to late-estrus. Metaestrus begins with the cessation of estrus and lasts for about 3 days. Primarily it is the period of the formation of corpus luteum (CL). The corpus luteum produces progesterone and maintains pregnancy in the ewe (Wildeus, 2000). When satisfactory results are not obtained under natural breeding conditions, it is possible to artificially manipulate the reproductive cycle of sheep. A common method of inducing estrus in non-cycling ewes is progesterone-based therapies. Progesterone prevents the ewe from returning to estrus and ovulating. It is produced by the corpus luteum (CL) of the ovary following ovulation and sustains pregnancy.

When Progestins are introduced artificially, they fool the body into thinking it is pregnant and the animal will not ovulate or come into estrous (heat). When the progesterone source is totally removed, the body realizes it is no longer pregnant and will ovulate within a very predictable period. Progestins refer to the synthetic compounds with the properties of progesterone (Wildeus, 2000). These substances mimic the function of the CL. Progestogens (synthetic analogs of progesterone) can be provided by feeding (MGA), implants under the skin (Synchro-Mate $B \circledR$ ), sponges (or pessaries) inserted into the vagina, or plastic delivery devices inserted into the vagina (CIDR). Intravaginal sponges (or pessaries) have been the traditional method of inducing and/or synchronizing estrus in ewes. They contain progestagens that are effective at lower doses than natural progesterone. Prostaglandin-based protocols are only applicable to cycling ewes and are restricted to use during the breeding season. The two commonly used products are Lutalyse ${ }^{\mathrm{TM}}$ (PGF2a) and Estrumate ${ }^{\circledR} \quad$ (cloprostenol). Prostaglandins cause regression of the $\mathrm{CL}$, telling the body than no pregnancy exists. The ewe will ovulate within a very predictable time. When a single treatment of prostaglandin is given to a flock of cycling ewes, 60 to 70 percent of the flock will exhibit a synchronized estrus beginning 30 to 48 hours later. A double injection system (11 days apart) is most common in sheep (Wildeus, 2000).

This study was designed first to investigate whether cypermethrin and Neocidol have effects on length of estrous cycle, estrous recyclicty and reproductive hormones in native ewes.

\section{MATERIALS and METHODS}

\section{Animals:}

In the current study twenty apparently healthy mature ewes of native breed were used. All animals were allowed to take $1.0-1.5 \mathrm{~kg}$ of cotton seed cake, $2 \mathrm{~kg}$ wheat straw and green fodders ad. Libitum (Barseem / Drawa) during the year.

\section{Chemical substances:}

\section{A. Diazinon (Neocidal 600 EC)}

The product obtained from Ciba Geigy Company, Basle, Switzerland as an emulsified concentrate. This concentrate contains $600 \mathrm{~g} / \mathrm{L}$ of diazinon [0, 0 diethyl-0-(2-isopropyl-6-methyl-4-pyrimdinyl) thiophosphate].

\section{B. Ectomin (Cypermethrin high cis)}

The product obtained from Ciba Geigy Company, Basle, Switzerland as an emulsified concentrate. This concentrate contains $200 \mathrm{~g} / \mathrm{L}$ of Cypermethrin high Cis (a pyrethroid).

\section{Estrus synchronization:}

Synchronization of estrus was performed by using veramix sheep sponges which contain medroxy progesterone acetate. Each sponge should be coated with antiseptic cream then the sponge inserted into the ewe's vagina and pushed gently as far as it will go. The sponges are removed after thirteen days, Ewes joined with vasoctomized ram the day after cessation of treatment and the animals come in estrus during the following 3-5 days. The breast of the ram was painted with a colored material, every morning. Ewes came in estrus were known from marks of the coloring material on their back and around the vulva and the ventral aspect of the tail. Examination of external genitalia and the secretion from the vulva of ewes were carried out. Furthermore the behavioral patterns, sexual receptivity and interest in the ram 
were also noted, the day in which the ram marked the female was considered the zero day. Estrus may be synchronized by 2 doses of PG, 9 days apart in ewes.

\section{Blood sampling:}

Blood samples $(10 \mathrm{ml})$ were collected from the jugular vein into a clean dry and sterilized plastic test tubes and left overnight There after blood samples were centrifuged at $3000 \mathrm{rpm}$ for 10 minutes $(50 \times \mathrm{g}$ value) to obtain the serum and stored at $-20{ }^{\circ} \mathrm{C}$.

\subsection{Progesterone (P4) Estimation:}

$\mathrm{P} 4$ concentration in serum was determined in duplicate using a direct solid phase RIA (coat $-\mathrm{A}$ count Progesterone ${ }^{\circledR}$, DPC, In the Middle Eastern Regional Radioisotope Centre for the Arab Countries, Dokki, using the specific Kits of Diagnostic Products Corporation, Los Angeles, USA). RIA depends on competition between I125 labeled progesterone (tracer) in a fixed time with the progesterone of a standard or sample for antibody sites (Abraham, 1981). The amount of labeled progesterone bound to the antibody is indirectly proportional to the concentration of $\mathrm{P} 4$ present in the tested serum or the standard. The antibody being immobilized to the wall of the polypylene, decanting the supernatant suffices to terminate the competition and to isolate the antibody bound fraction of the radiolabeled progesterone tubes were counted in gamma counter, and then yields a number which is converted by using a standard curve to measure the progesterone in the samples (Abraham, 1981).

\subsection{Estimation of Follicular Stimulating Hormone (FSH) profiles}

FSH concentration in serum was determined using a direct solid phase RIA, DPC, In the Middle Eastern Regional Radioisotope Centre for the Arab Countries, Dokki, using the specific Kits of Diagnostic Products Corporation, Los Angeles, USA).

\subsection{Estimation of Luteinizing Hormone (LH) profiles:}

The circulating concentrations of LH were determined by radioimmunoassay in the Middle Eastern Regional Radioisotope Centre for the Arab Countries, Dokki, using the specific Kits of Diagnostic Products Corporation (Los Angeles, USA). Double antibody $\mathrm{LH}$ procedure is based on highly specific anti LH antibody, $\mathrm{I}^{125}$ tracer and calibrators consisting of purified iodination grade LH in a serum matrix. Sample and antibody are preincubated; then, radiolabeled LH competes with LH in the sample for antibody sites during a second incubation step. The antibody - bound fraction is precipitated and counted. Finally, the concentration of the tested samples is detected from a calibration curve (Santner et al., 1981 and Zia and Coombes, 1981).

\section{Statistical analysis:}

Throughout the experimental study, the obtained data were subjected to statistical analysis (Snedecor and Cochran, 1982). To determine Serum progesterone concentrations were analyzed by least-squares analysis of variance using the GLM procedure (SAS 2004). All values are expressed as mean \pm SE. The analyses of circulating FSH and LH concentrations were performed using theMIXED procedure (SAS 2004).

\section{RESULTS}

\section{Effect of neocidol and ectomin on estrous cycle and hormonal profiles}

\subsection{Effect of neocidol and ectomin on estrous recyclicity}

The current results revealed that spraying of ewes by either neocidol or ectomin by the proper dose $(1 / 1000$ and 1/500 respectively) had no impairment effect on the estrous recyclicity. It was also noticed that the treatment of ewes with neocidol during the breeding season had no significant $(\mathrm{p}<0.05)$ effect on the length of estrous cycle. The length of estrous cycles were $17 \pm 0.27,18.66 \pm 0.57$ and $18 \pm 0.27$ days in the first, second and third estrous cycle of the treated ewes respectively rather than $18.36 \pm 0.85$ days in the control ewes. Also treatment of ewes by spraying with ectomin, had no significant $(\mathrm{p}<0.05)$ effect on the length of estrous cycle. The length of estrous cycle was $18.36 \pm 0.85$ days in the control ewes, while they were $17 \pm 0.69,18.28 \pm 0.49$ and $17.4 \pm 0.55$ days in the first, second and third estrous cycle of the treated ewes respectively.

\subsection{Effect of neocidol and ectomin on progesterone (P4) profiles}

Neither neocidol nor ectomin had no significant influence on the classical pattern of P4 profiles, this classical pattern, represented in fig. $(1,2)$ in the form of basal level during estrus phase ( 0 day) increased gradually from day 3 to day6. Then a peak level of recorded from day 9 to day 12 then decline again on day 15. Also there was no significant difference in the basal P4 level ( 0 day) between neocidol treated ewes and the control (Table 1 and Fig. 1). There was a slight decrease in P4 concentration on this day in the ectomin treated ewes $(0.45 \pm 0.1$ rather than $0.68 \pm 0.04 \mathrm{ng} / \mathrm{ml}$ ) serum of the control on the third cycle followed the treatment. On the other hand, a slight decrease of P4 level on day 3 of the second cycle in neocidol treated ewes $(1.10 \pm 0.06 \mathrm{ng} / \mathrm{ml}$ rather than $1.41 \pm 0.05 \mathrm{ng} / \mathrm{ml}$ in the control. A significant decrease $(\mathrm{p}<0.05)$ of $\mathrm{P} 4$ concentration was observed on day 6 of the third cycle of estrous followed neocidol treatment $(1.85 \pm 0.07 \mathrm{ng} / \mathrm{ml} \mathrm{vs}$ $2.38 \pm 0.13 \mathrm{ng} / \mathrm{ml}$ in the control). 
On day 9 a significant $(\mathrm{p}<0.09)$ decrease of $\mathrm{P} 4$ concentration was observed on the $3^{\text {rd }}$ estrous cycle followed neocidol treatment (table 1). On day 12 a significant $(\mathrm{p}<0.05)$ decrease of $\mathrm{P} 4$ concentration was observed on the $2^{\text {nd }}$ and $3^{\text {rd }}$ estrous cycles followed neocidol treatment (table 1 and fig. 1). on the other hand a significant $(\mathrm{p}<0.05)$ decrease of $\mathrm{P} 4$ concentration was observed on day 9 of estrous cycle after ectomin treatment (table 1 and fig. 2).

Table 1: Effect of neocidol and ectomin on progesterone (P4) profiles during estrous cycle of ewes

\begin{tabular}{|c|c|c|c|c|c|c|c|}
\hline \multirow{3}{*}{$\begin{array}{l}\text { Days } \\
\text { of EC }\end{array}$} & \multicolumn{7}{|c|}{$\mathrm{P} 4$ concentrations $(\mathrm{ng} / \mathrm{ml})$} \\
\hline & \multirow{2}{*}{$\begin{array}{l}\text { Control } \\
(\mathrm{n}=8)\end{array}$} & \multicolumn{3}{|c|}{ Neocidol treated ewes $(n=6)$} & \multicolumn{3}{|c|}{ Ectomin treated ewes $(\mathrm{n}=6)$} \\
\hline & & $1^{\text {st }}$ cycle & $2^{\text {nd }}$ cycle & $3^{\text {rd }}$ cycle & $1^{\text {st }}$ cycle & $2^{\text {nd }}$ cycle & $3^{\text {rd }}$ cycle \\
\hline 0 & $0.68 \pm 0.04$ & $0.62 \pm 0.06^{\mathrm{a}}$ & $0.96 \pm 0.35^{\mathrm{a}}$ & $0.66 \pm 0.04^{\mathrm{a}}$ & $0.62 \pm 0.03^{\mathrm{a}}$ & $0.72 \pm 0.08^{\mathrm{a}}$ & $0.45 \pm 0.1^{\mathrm{b}}$ \\
\hline 3 & $1.41 \pm 0.05^{\mathrm{ab}}$ & $1.40 \pm 0.05^{\mathrm{a}}$ & $1.10 \pm 0.06^{\mathrm{c}}$ & $1.24 \pm 0.03^{\mathrm{bc}}$ & $1.53 \pm 0.15$ & $1.49 \pm 0.20$ & $1.51 \pm 0.22$ \\
\hline 6 & $2.38 \pm 0.13^{\mathrm{a}}$ & $2.45 \pm 0.08^{\mathrm{a}}$ & $2.13 \pm 0.12^{\mathrm{ab}}$ & $1.85 \pm 0.07^{\mathrm{b}}$ & $2.61 \pm 0.19$ & $2.71 \pm 1.10$ & $1.91 \pm 0.07$ \\
\hline 9 & $3.83 \pm 0.14^{\mathrm{a}}$ & $3.56 \pm 0.17^{\mathrm{a}}$ & $3.75 \pm 0.12^{\mathrm{a}}$ & $3.06 \pm 0.04^{\mathrm{b}}$ & $3.19 \pm 0.29^{\mathrm{b}}$ & $2.67 \pm 0.21^{\mathrm{bc}}$ & $2.56 \pm 0.17^{\mathrm{c}}$ \\
\hline 12 & $4.92 \pm 0.24^{\mathrm{a}}$ & $4.80 \pm 0.15^{\mathrm{ab}}$ & $4.18 \pm 0.26^{\mathrm{bc}}$ & $3.99 \pm 0.06^{\mathrm{c}}$ & $4.45 \pm 0.40^{\mathrm{ab}}$ & $3.99 \pm 0.33^{\mathrm{bc}}$ & $3.54 \pm 0.32^{\mathrm{c}}$ \\
\hline 15 & $1.18 \pm 0.11$ & $1.72 \pm 0.09$ & $1.02 \pm 0.06$ & $1.07 \pm 0.02$ & $1.27 \pm 0.08$ & $1.32 \pm 0.07$ & $1.09 \pm 0.11$ \\
\hline
\end{tabular}

$\mathrm{Ec}=$ Estrous cycle, $\mathrm{n}=$ Number

Values with different superscript letters $(a, b, c)$ in the same row were significantly $(p<0.05)$ differ.
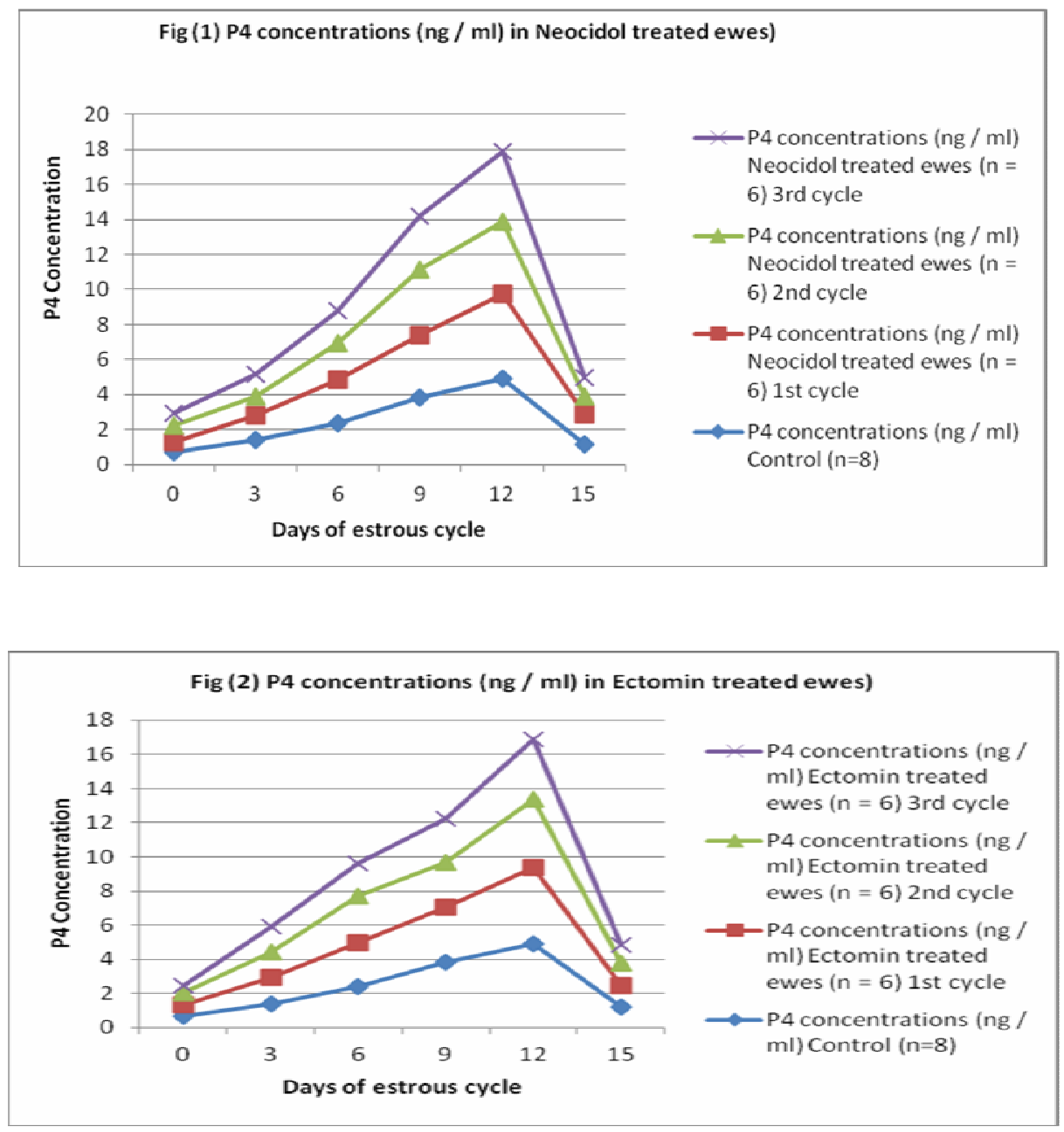


\subsection{Effect of neocidol and ectomin on Follicle Stimulating Hormone (FSH) profiles}

The obtained results showed that a similar pattern of FSH in the control, neocidol and ectomin treated ewes. This pattern was in the form of two elevated peaks on zero and first day of estrous cycle and fluctuated till the end of estrous cycle (Table 2, Fig. 3 \&4).

Table 2: Effect of neocidol and ectomin on Follicle Stimulating Hormone (FSH) profiles during estrous cycle of ewes.

\begin{tabular}{cccccccc}
\hline \multirow{2}{*}{$\begin{array}{c}\text { Days } \\
\text { of EC }\end{array}$} & \multicolumn{7}{c}{ FSH concentration $(\mathrm{mIU} / \mathrm{ml})$} \\
\cline { 2 - 7 } & $\begin{array}{c}\text { Control } \\
(\mathrm{n}=8)\end{array}$ & \multicolumn{2}{c}{ Neocidol treated ewes $(\mathrm{n}=6)$} & \multicolumn{2}{c}{ Ectomin treated ewes $(\mathrm{n}=6)$} \\
\cline { 2 - 8 } & $1^{\text {st }}$ cycle & $2^{\text {nd }}$ cycle & $3^{\text {rd }}$ cycle & $1^{\text {st }}$ cycle & $2^{\text {nd }}$ cycle & $3^{\text {rd }}$ cycle \\
\hline 0 & $35.12 \pm 3.08$ & $30.63 \pm 0.86$ & $28.17 \pm 2.47$ & $27.64 \pm 0.67$ & $32.56 \pm 2.79$ & $29.45 \pm 2.81$ & $29.66 \pm 2.68$ \\
\hline 1 & $22.04 \pm 1.41$ & $2.45 \pm 1.11$ & $20.86 \pm 1.20$ & $20.00 \pm 0.52$ & $20.85 \pm 0.74$ & $19.74 \pm 0.20$ & $20.68 \pm 1.79$ \\
\hline 4 & $7.82 \pm 0.42$ & $2.75 \pm 0.23$ & $1.75 \pm 0.21$ & $2.66 \pm 0.19$ & $5.53 \pm 0.73$ & $4.04 \pm 0.59$ & $2.82 \pm 0.32$ \\
\hline 8 & $3.09 \pm 0.28$ & $7.18 \pm 0.28$ & $5.30 \pm 0.47$ & $6.89 \pm 0.29$ & $4.05 \pm 0.50$ & $4.07 \pm 0.50$ & $6.69 \pm 0.59$ \\
\hline 12 & $8.73 \pm 0.36$ & $6.93 \pm 0.34$ & $7.32 \pm 0.27$ & $3.55 \pm 0.44$ & $6.71 \pm 0.33$ & $5.25 \pm 0.63$ & $4.75 \pm 0.72$ \\
\hline 16 & $5.38 \pm 0.57$ & $5.55 \pm 0.44$ & $5.00 \pm 0.54$ & $4.84 \pm 0.37$ & $7.84 \pm 0.13$ & $7.97 \pm 0.31$ & $5.36 \pm 0.59$ \\
\hline
\end{tabular}

$\mathrm{Ec}=$ Estrous cycle, $\mathrm{n}=$ Number
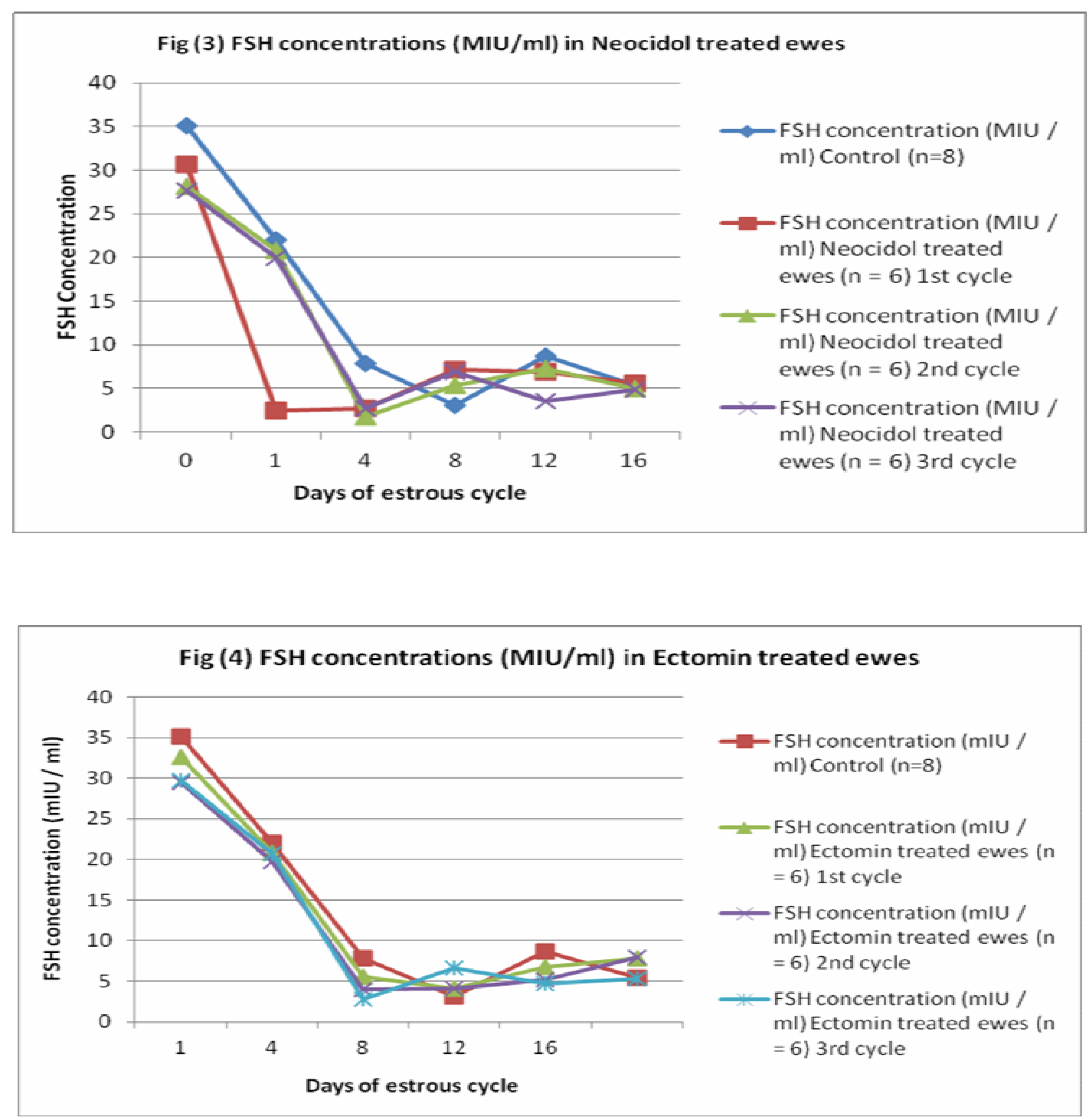


\subsection{Effect of neocidol and ectomin on Luteinizing Hormone (LH) profiles}

LH pattern during estrous cycle was similar in the control and neocidol and ectomin treated ewes. One peak only was recorded at zero day in the three estrous cycles then the level was fluctuated all over the experimental period in all treated and control ewes (table 3, Fig. 5\&6).

Table 3: Effect of neocidol and ectomin on Luteinizing Hormone (LH) profiles during estrous cycle of ewes.

\begin{tabular}{|c|c|c|c|c|c|c|c|}
\hline \multirow{3}{*}{$\begin{array}{c}\text { Days of } \\
\text { EC }\end{array}$} & \multicolumn{7}{|c|}{ LH concentration (mIU / ml) } \\
\hline & \multirow{2}{*}{$\begin{array}{l}\text { Control } \\
(n=8)\end{array}$} & \multicolumn{3}{|c|}{ Neocidol treated ewes $(n=6)$} & \multicolumn{3}{|c|}{ Ectomin treated ewes $(\mathrm{n}=6)$} \\
\hline & & $1^{\text {st }}$ cycle & $2^{\text {nd }}$ cycle & $3^{\text {rd }}$ cycle & $1^{\text {st }}$ cycle & $2^{\text {nd }}$ cycle & $3^{\text {rd }}$ cycle \\
\hline 0 & $21.41 \pm 1.50$ & $19.28 \pm 0.84$ & $18.48 \pm 0.49$ & $17.15 \pm 1.74$ & $19.29 \pm 0.63$ & $18.68 \pm 0.76$ & $17.83 \pm 0.36$ \\
\hline 1 & $9.62 \pm 0.58$ & $7.83 \pm 017$ & $8.28 \pm 0.53$ & $7.88 \pm 0.34$ & $7.73 \pm 0.46$ & $8.50 \pm 0.20$ & $8.25 \pm 0.76$ \\
\hline 4 & $2.65 \pm 0.24$ & $3.68 \pm 0.17$ & $4.40 \pm 0.15$ & $2.84 \pm 0.13$ & $4.68 \pm 0.19$ & $2.37 \pm 0.16$ & $2.78 \pm 0.15$ \\
\hline 8 & $4.65 \pm 0.30$ & $4.96 \pm 0.17$ & $3.43 \pm 0.24$ & $4.46 \pm 0.12$ & $5.11 \pm 0.16$ & $4.33 \pm 0.13$ & $4.11 \pm 0.07$ \\
\hline 12 & $4.41 \pm 0.17$ & $3.28 \pm 0.04$ & $3.64 \pm 0.22$ & $3.21 \pm 0.18$ & $3.52 \pm 0.21$ & $2.66 \pm 0.28$ & $2.27 \pm 0.15$ \\
\hline 16 & $1.91 \pm 0.19$ & $0.96 \pm 0.08$ & $1.03 \pm 0.07$ & $0.97 \pm 0.12$ & $1.05 \pm 0.06$ & $1.15 \pm 0.16$ & $0.93 \pm 0.06$ \\
\hline
\end{tabular}

Ec $=$ Estrous cycle, $n=$ Number
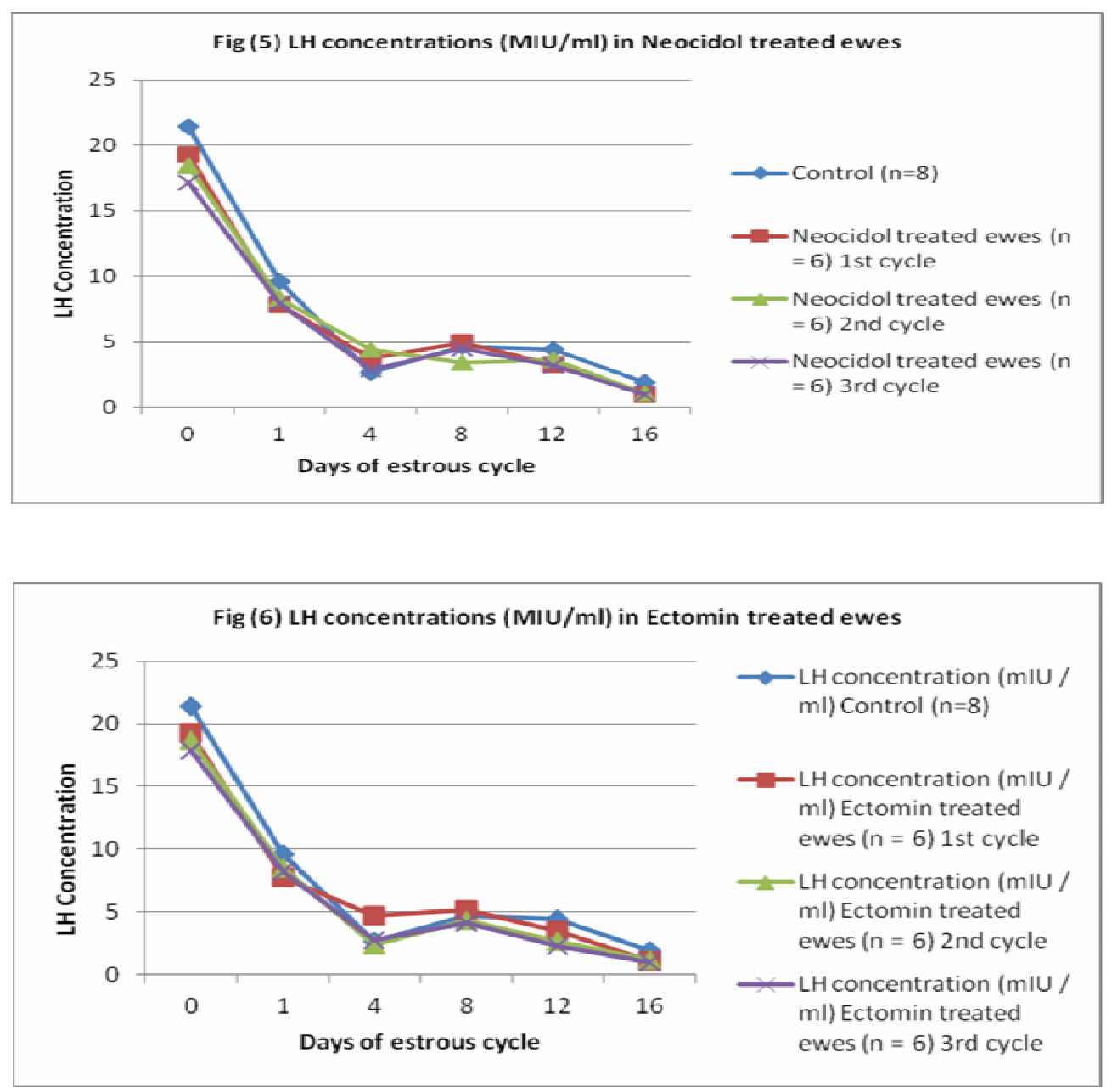


\section{DISCUSSION}

The effect of neocidol and ectomin on estrous cycle length and ovarian recyclicity was assessed. In the current study the obtained results revealed that spraying of ewes (two times daily for 15 days interval) with neocidol (1/1000) and ectomin (1/500) had no deleterious effect on ovarian recyclicty or on estrous cycle length. This result was in agreement with the previous study reported by Abd El-Daim (1993) who found that cyfluthrin (a synthetic pyrethroid) had no clear side effect on the estrous cycle length and reproductive behavior in buffalocows.

On the other hand Huber (1965), Good et al. (1965) and Eraschenko and Wilson (1979) reported that using of some insecticides as chlordecone produced profound disturbance in the reproductive physiology of adult female rats exposed chronically to the drug

with a loss of fertility associated with persistent vaginal estrous and failure of ovulation. Moreover, Cannon and Kimbrough (1979) investigated that reproduction in adult female rats completely inhibited when the animals fed the insecticide Kepone at graduated concentration up to $25 \mathrm{ppm}$ for 3 months and reproductive ability was restored 2 months after exposure.

The disturbance on reproductive ability of rats may be due to the systemic and chronic treatment rather than skin application for short time which was done in the present study in ewes. Also the variation in the insecticide used, dosage, duration of the experiment and route of administration beside the difference in the experimental animal used in our study. In addition, Ohi et al. (2004) studied the adverse effects of fipronil (phenylpyrazole) on reproductive function in Wistar rats and found that exposure lengthened the estrous cycle, decreased plasma progesterone and estradiol levels, and reduced the pregnancy index.

The cyclic P4 pattern of ewes was not affected by neocidol or ectomin treatment, this pattern was similar to that described by Thorburn et al. (1969) and Elias, (1987) for the normal ewes, on the hand, P4 concentrations of the first estrous cycle followed treatment was also significantly $(\mathrm{p}<0.01)$ affected by neocidol and ectomin, this observation came in agreement with Shalaby, (1989) who reported that P4 was measured in the first days of pregnancy of ewes treated with cyfluthrin directly after mating and this may reflect the slow absorption of insecticides through the skin. However, the significant decrease of the peak on days $(9-12)$ in the $2^{\text {nd }}$ and $3^{\text {rd }}$ estrous cycles follow either neocidol or ectomin treatment without alteration of $\mathrm{P} 4$ pattern and the ovarian recyclicty was in agreement with Shalaby, (1989) who found slight decrease in $\mathrm{P} 4$ concentration after cyfluthrin treatment, latter on during early pregnancy, this may be due to absorption of small amounts of these reagents t5hrough the mucous membranes or through very small abrasions in the skin.

The gonadotoxic and ovarian hormone disturbance (P4 and estrogen) were also found (Trifonova, 1984) by systemic treatment of female rats for 2-3 months with some insecticides. On the other hand, systemic treatment with organophosphrous compounds and pyrethroid in female dogs and foxes had no any deleterious effect on $\mathrm{P} 4$ pattern or its concentration during estrous cycle (Gombe and Odour Okelo, 1983; Berge et al., 1983). Moreover, Glyphosate, organophosphates, organotins, phenoxyherbicides, and pyrethroid insecticides have been reported to affect sex hormone levels or function both directly and indirectly (Garry et al., 2003). Ohi et al. (2004) studied the adverse effects of fipronil (phenylpyrazole) on reproductive function in Wistar rats and found that exposure lengthened the estrous cycle, decreased plasma progesterone and estradiol levels, and reduced the pregnancy index.

The present results denotes that there is no significant effect neither in the pattern nor in the concentration of FSH and LH hormones in ewes sprayed with neocidol or ectomin insecticides in recommended doses $(1 / 1000$ and $1 / 500)$ respectively, this may be due to the short time exposure through skin application of the insecticide used. The absence of any effect on the these hormones in the three cycles followed the application of neocidol and ectomin may also due to the short half life of LH and FSH in ovine serum (Elias, 1991) which may not allow any accidental effect of insecticides. In contrary with progesterone which was present during almost the days of estrous cycle except around heat time (Elias, 1987).

On the other hand, other investigations reported that when organophosphrous compounds or pyrethroids was used in female rats in high doses for long period and systemic application, they affect hypothalamus and pituitary gland with resultant inhibition of the FSH and LH release (Nakazawa, 1974). While Droain and Labriae, (1981) mentioned that chlordecone increased serum prolactin and decreased $\mathrm{LH}$ in ovarictomized female rat. It had minor effects on basal LH levels; also it failed to mine the complete neural and / or pituitary response to estrogen. Several authors reported a variety of neurotransmitter alterations following some insecticides treatment as chlordecone (Chang-Tsue and Ho, 1980 and Seth et al., 1981).

Berge and Nafstad (1983) revealed that values of LH in two of the control blue fox were higher than those recorded in the medicated group which orally administered fenchlorophos 3 days before estrus similar results were also recorded by Chapin et al. 
(1982) found that the chronic administration of 2, 5, hexandione to rats failed to produce marked changes in the circulating levels of LH and FSH hormones at any time measured. The significant changes in levels of both $\mathrm{LH}$ and FSH hormones in ewes treated topically with both insecticides (neocidol or ectomin) may be attributed to the minor or no effect of the insecticides on hypothalamic nuclei concerned with reproductive control.

This opinion was supported by short time of application and smaller dosage used (therapeutic doses). Garry et al. (2003) investigated pesticide applicators and found increases in testosterone, FSH, and LH in the fall (after pesticide exposure had declined) compared to the summer. Padungtod et al. (1998) investigated pesticide factory workers exposed to organophosphate pesticides and found that serum LH increased with exposure. They hypothesized that pesticide exposure caused testicular damage because reproductive hormone levels correlated with semen parameters among exposed workers. Oliva et al. (2001) also found that men exposed to pesticides (broadly defined as "'herbicides, fungicides, insecticides, fumigants, and rodenticides") had higher serum estradiol concentrations.

Fenvalerate (Fen), a type II pyrethoid, causes reproductive abnormalities in male rats. For example, serum FSH and $\mathrm{LH}$ increased with exposure, and testosterone level in testicular homogenates decreased, in male rats dosed at $12 \mathrm{mg} / \mathrm{kg}$ (Hu et al., 2002). Exposure to Fen at one-fifth the LC50 led to reduced testicular weights, reduced epididymal sperm counts, decreased sperm motility, and decreased serum testosterone levels, in male rats (Mani et al. 2002). Ping Liu et al. (2006) showed that cypermethrin plus methyl parathion at dose of $1 / 30$ LD50, the most of index indicated addictive interaction; while the effects on relative weights of ovaries was antagonistic, and the effect on estradiol was synergistic interaction in female rats, whereas it was addictive interaction in male rats, whose estradiol level could be increased $64.64 \%$ by cypermethrin exposure.

The serum FSH and estradiol increased in both male and female rats exposed to the pesticide mixture, the estradiol almost 2-fold, but LH did not change after exposure to the two pesticide mixtures at doses of 1/30 LD50 and 1/135 LD50. The testosterone results were equivocal; among males the high dose group had higher levels than the low-dose group, but levels in the high-dose group did not exceed those in control animals. These results are difficult to interpret. The reproductive hormone findings suggest that mixed pesticide exposure even at low doses may interfere with reproductive hormones and enhance FSH and estradiol concentrations. Increased estradiol may in turn affect male reproductive health (Ping Liu et al., 2006).

\section{Conclusions}

From the current study we concluded that neither cypermethrin nor Neocidol had adverse effects on length of estrous cycle, estrous recyclicty and reproductive hormones in native ewes when sprayed by the proper dose (1/1000 and 1/500 respectively).

\section{REFERANCES}

Abd-El-Daim, G.A. (1993): Effects of Pyrethroid on some reproductive aspects in non pregnant buffaloes. Ph.D. (Pharmacology) Cairo University, Giza, Egypt.

Abraham, G.E. (1981): The application of natural steroid radioimmunoassay to gynecologic endocrinologic radioassay systems in clinical endocrinology. Abraham, Ed. (Basel: Marcel Dekkers).

Ahmed, S.A. (2000): The immune system as a potential target for environmental estrogens (endocrine disrupters): a new emerging field. Toxicology, 150: 191-206.

Berge, G.N. and Nafstad, I. (1983): Teratogenicity and embryotoxicity of orally administered fenchlorphos in blue foxes. Acta Vet. Scand., 24(1): 99-112.

Cannon, S.B. and Kimbrough, R.D. (1979): Short term chlordecone toxicity in rats including effects on reproduction, pathological organ changes and their reversibility. Toxicol. Appl. Pharmacol., 47: 469-476.

Chang-Tsui, Y.Y.H. and Ho, I.K. (1980): Effects of Kepone (chlordecone) on synaptosomal gaminobutyric acid uptake in the mouse. Neurotoxicology, 1(2): 357-367.

Chapin, R.E.; Norton, R.M.; Pop, J.A. and Bus, J.S. (1982): The effect of 2, 5- Hexandione on reproductive hormones and testicular enzyme activities the F- 344 rat. Toxicol. Appl. Pharmacol., 62: 262-272.

Droain, J. and Labriae, F. (1981): Interactions between 17- $\beta$ estradiol and progesterone in the control of luteinizing hormone and follicle stimulating hormone release in rat anterior pituitary. Endocrinology, 108: 52-57.

Elias, A.N. (1987): Changes of Hormonal level throughout the estrous cycle in sheep with special emphasis to progesterone. M.V. SC. Thesis (Animal Physiology) Fac. Vet. Med., Cairo University, P 3-26.

Elias, A.N. (1991): Studies on some endocrinological aspects for control of ovulation in local sheep. Ph.D., Thesis (Animal Physiology) Fac. Vet. Med., Cairo University, P 4-40.

Eraschenko, V.P. and Wilson, W.O. (1979): Cellular changes in the gonads, liver and adrenal glands of Japanese quail as affected by the insecticide kepone. Toxicol. Appl. Pharmacol., 31: 491. 
Garey, J. Wolff, M.S. (1998): Estrogenic and antiprogestagenic activities of pyrethroid insecticides. Biochem. Biophys. Res. Commun, 251(3): 855-859.

Garry, V.F.; Holland, S.E.; Erickson, L.L. and Burroughs, B.L. (2003): Male reproductive hormones and thyroid function in pesticide applicators in the Red River Valley of Minnesota. J Toxicol Environ Health A., 66(11): 965-986.

Gombe, S. and Odour Okelo. (1983): Chronic (90) days toxicity of pyrethrum in German Shepherd dogs. Kenya Veterinarian, 7(2): 4.

Good, E.E.; Ware, G.W. and Miller, D.F. (1965): Effects of insecticides on reproduction in the lab. Mouse. J. Econ. Entomol., 38: 754.

Huber, J.J. (1965): Some physiological effects of the insecticide kepone in the male mouse. Toxicol. Appl. Pharmacol., 7: 56.

Hu, J.Y.; Wang, S.L.; Zhao, R.C.; Yang, J.; Chen, J.H.; Song, L. and Wang, X.R. (2002): Effects of fenvalerate on reproductive and endocrine systems of male rats [in Chinese]. Zhong Hua Nan Ke Xue, 8(1): 18-21.

Institoris, L.; Siroki, O.; Undeger, U.; Desi, I.; Nagymajtenyi, L. (1999):Immunotoxicological effects of repeated combined exposure by cypermethrin and the heavy metals lead and cadmium in rats. Int. J. Immunopharmacol, 21(11): 735-743.

Landrigan, P.J.; Claudio, L.; Markowitz, S.B.; Berkowitz, G.S.; Brenner, B.L. and Romero, H. (1999): Pesticides and inner-city children: exposures, risks, and prevention. Environ. Health Perspect, 107(Suppl. 3): 431-437.

Mani, U.; Islam, F.; Prasad, A.K.; Kumar, P.; Kumar, V.S.; Maji, B.K. and Dutta, K.K. (2002): Steroidogenic alterations in testes and sera of rats exposed to formulated Fenvalerate by inhalation. Hum. Exp. Toxicol., 21: 593-597.

Nakazawa, T. (1974): Choronic organophosphrous intoxication in women. J. Jpn. Associ. Rural Med., 22: 756-758.

Ohi, M.; Dalsenter, P.R.; Andrade, A.J.M. and Nascimento, A.J. (2004): Reproductive adverse effects of fipronil in Wistar rats. Toxicol. Lett., 146(2): 121-127.
Oliva, A.; Spira, A. and Multigner, L. (2001): Contribution of environmental factors to the risk of male infertility. Hum. Reprod., 16(8): 1768-1776.

Padungtod, C.; Lasley, B.L.; Christiani, D.C.; Ryan, L.M. and Xu, X. (1998): Reproductive hormone profile among pesticide factory workers. J. Occup. Environ. Med., 40(12): 1038-1047.

Ping Liu; Xiaoxiao Song; Weihong Yuan; Weihua Wen; Xinan Wu; Jian Li and Xuemin Chen, (2006): Effects of cypermethrin and methyl parathion mixtures on hormone levels and immune functions in Wistar rats. Arch. Toxicol., 80: 449-457.

Seth, P.K.; Agruwal, A.K. and Bandy, S.C. (1981): Biochemical changes in the brain consequent dietary exposure of developing and mature rats to chlordecone (kepone). Toxicol. Appl. Pharmacol., 54: 262.

Shalaby, S.I. (1989): Effects of insecticides on different stages of pregnancy of Barki ewes. Ph.D. Thesis, Theriogenology. Fac. Vet. Med. Alexandria University.

Sortur, S.M. and Kaliwal, B.B. (1999): Effect of methyl parathion formulation on estrous cycle and reproductive performance in albino rats. Indian J. Exp. Biol., 37(2): 176-178.

Thorburn, G.D.; Basset, J.M. and Smith, I.D. (1969): Progesterone concentration in Peripheral plasma of sheep during the estrous cycle. J. Endocrinology, 45: 459-469.

Trifonova, T.K. (1984): Effect of pesticides on reproductive function in animals. Veterinarya; Moscow, USSR NO. 8155.

Wildeus, S. (2000): Current concepts in synchronization of estrus: Sheep and goats. Proceedings of the American Society of Animal Science, Agricultural Research Station, Virginia State University, Petersburg 23806.

Yousef, M.I.; El-Demerdash, F.M.; Al-Salhen, K.S. (2003): Protective role of isoflavones against the toxic effect of cypermethrin on semen quality and testosterone levels of rabbits. J. Environ. Sci. Health B., 38(4): 463-478. 
هل تعرض النعاج للمبيدات الحشرية (النيوسيدول أو السيبرميثرين) يؤثر سلبيا على دورة المبيض والصورة الهرمونية للجهاز

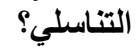

عبد العظيم على خلف ، بكار رمضان عبد الطليم

أجريت هذه الدراسة لمعرفة هل تعرض النعاج للمبيدات الحشرية (النيوسيدول والسييرميثرين) يؤثر سلبيا على طول دورة الثبقى، دورة المبيض

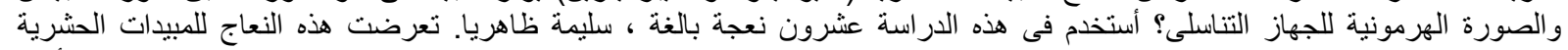

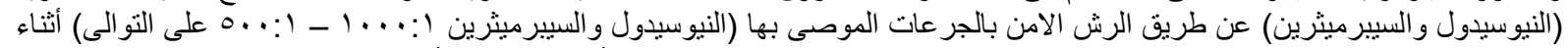

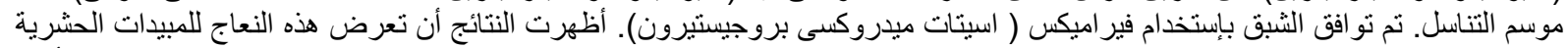

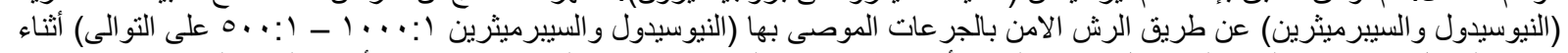

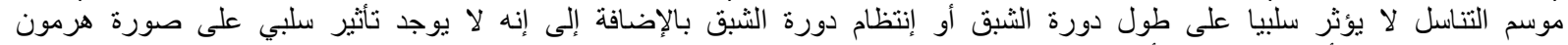

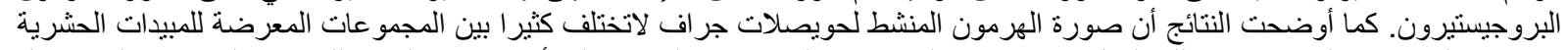

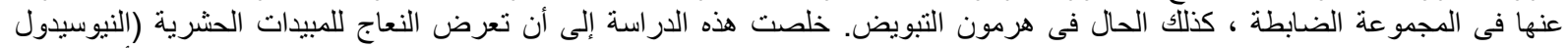

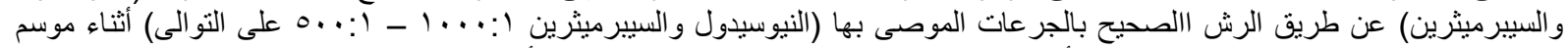

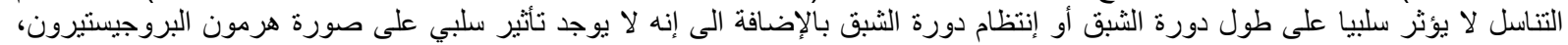
الهرمون المنشط لحويصلات جر اف وهرمون التبويض. 